\title{
pro.posições
}

ISSN 1980-6248

10.1590/1980-6248-2014-0124

ARTIGOS

\section{S. Vigotski e o ensino de arte: "A educação estética" (1926) e as escolas de arte na Rússia 1917-1930}

\section{L.S. Vygotsky and Teaching Arts: "The aesthetic education" (1926) and the Art Schools in Russia 1917-1930}

Luana Maribele Wedekin*

Andrea Vieira Zanella**

*Universidade Estadual Paulista (UNESP), Departamento de Artes e Representação Gráfica, Bauru, São Paulo, Brasil. luana@faac.unesp.br

**Universidade Federal de Santa Catarina (UFSC), Pós-Graduação em Psicologia, Florianópolis, Santa Catarina, Brasil. avzanella@gmail.com

\begin{abstract}
Resumo
Problematizam-se, neste artigo, as relações entre "A educação estética" (1926), de Lev S. Vigotski, e o contexto de reestruturação da educação e do ensino das artes após a Revolução Russa de outubro de 1917. Trata-se de pesquisa bibliográfica que operou um diálogo entre Vigotski e os historiadores que estudaram as escolas de arte anteriores e posteriores à Revolução de 1917. Orientaram as análises as seguintes questões: as ideias de Vigotski sobre estética estavam em consonância com as práticas estabelecidas nessas novas instituições? Como essas ideias se relacionavam com as políticas para o ensino de arte no período? Constatou-se que "A educação estética" foi forjada na experiência prática de Vigotski em diálogo com a arte e a ciência de sua época, pautada em pensamento independente dos encaminhamentos oficiais, mas cuja qualidade das reflexões e dos princípios garante a atualidade e a potência da obra para pensar o ensino de arte hoje.

Palavras-chave: Vigotski, educação estética, ensino de arte, arte russa.
\end{abstract}

\footnotetext{
1 Apoio: Coordenação de Aperfeiçoamento de Pessoal de Nível Superior - Capes
} 


\title{
pro.posıções
}

\begin{abstract}
This article discusses the relationship between "The Aesthetic Education" (1926) by Lev S. Vigotski and the context of restructuring education and teaching of the arts after the Russian Revolution of October 1917. This bibliographical study creates a dialogue between Vigotski and historians who have researched the art schools before and after the Revolution of 1917. The following issues guide the analysis: Were Vigotski's ideas on aesthetics consistent with established practices in these new institutions? Were these ideas related to policies for teaching art in the period? We concluded that "The Aesthetic Education" was forged on Vigotski's practical experience in dialogue with the art and science of his time. The author remained independent of the official thinking, what keeps his work relevant and powerful to think about teaching arts today.

Keywords: Vigotski, aesthetic education, teaching arts, Russian art.
\end{abstract}

\section{Introdução}

É objetivo deste artigo problematizar as relações entre o capítulo "A educação estética”, parte da obra Psicologia pedagógica (1926/2001), de Lev S. Vigotski, e o contexto de profunda reestruturação da educação e do ensino das artes no período logo após a Revolução de outubro de 1917 na Rússia. O capítulo “A educação estética”, escrito, segundo Blanck (2003), entre 1921 e início de 1924, pode ser compreendido como resultado das atividades de Vigotski como professor de disciplinas ligadas à arte. O livro Psicologia pedagógica, por sua vez, resulta do interesse de Vigotski pela pedagogia e, de modo mais amplo, faz parte dos esforços empreendidos pela administração soviética para capacitação de professores. O censo de 1926 revelava a urgência do empreendimento: no contexto rural, aproximadamente $50 \%$ da população possuía alguma habilidade básica para ler e escrever, havendo apenas 107.900 professores profissionais no campo, numa proporção de 1 professor para cada 705 habitantes (Rosenberg, 1984).

É preciso relacionar essa produção de Vigotski igualmente com a Nova Política Econômica (1921-1928), na qual foram criadas várias medidas para a reestruturação da 


\section{pro.posıções}

economia após a guerra civil (1918-1921), especialmente a recuperação da agricultura e da indústria. A capacitação de professores era estratégia fundamental para a realização de tal tarefa. Psicologia pedagógica, de Vigotski, é, então, uma obra dirigida a professores, um texto de divulgação científica (Toassa, 2013b).

Em “A educação estética”, Vigotski estabelece um diálogo com alguns dos principais referenciais acerca do tema e apresenta seus pressupostos de forma clara e didática, como conviria a um instrumento pedagógico. O estudo de "A educação estética" revela algumas premissas importantes defendidas por Vigotski nesse campo específico, como a defesa da autonomia da educação estética, que, para o autor, não deve estar subordinada à moral, ao conhecimento relativo a outras disciplinas ou simplesmente destinada a oferecer atividades prazerosas. Para os objetivos deste artigo, interessa problematizar as ideias estéticas de Vigotski em diálogo com os princípios de algumas das instituições de ensino de arte criadas logo após a Revolução de outubro de 1917, justificando sua relevância em virtude do interesse crescente de pesquisadores pela temática na atualidade (Amorim; Castanho, 2008; Camargo; Bulgacov, 2008; Pereira, 2012; Peric, 2013; Pino, 2006; Pino, Schlindwein e Neitzel, 2010; entre outros).

No período de 1918 até grande parte da década de 1920, o clima na Rússia era de muitos debates sobre o papel da arte e do artista na revolução, revelando tensões entre perspectivas opostas, ao mesmo tempo em que havia o sentimento de que todas as possibilidades estavam abertas. Essa liberdade beneficiou especialmente o campo das artes na experimentação de novas formas de arte e também no seu ensino. Foram criadas novas escolas, cujos programas estavam em constante fluxo e mudança. A descrição sintética da estrutura de tais instituições serve aqui ao escopo de apresentar o contexto de Vigotski como campo de discussão e inovação, para o qual o seu "A educação estética" também viria a contribuir.

A produção do período de Gomel da obra de Vigotski tem recebido certa atenção, como os escritos de Toassa (2013a, 2013b) sobre Psicologia pedagógica, ora ao contextualizar a obra historicamente, seus objetivos e influências, ora ao discutir sua tradução para o português, identificar suas referências epistemológicas e teóricas. Martins (2010) analisa essa obra como parte do projeto psicológico de Vigotski. Barros, Camargo e Rosa (2011) empreendem um levantamento das experiências de Vigotski com o teatro, associando-as com 


\section{pro.posições}

sua obra Psicologia da arte (1998). Entretanto, a relação dos escritos de Vigotski com seu contexto artístico tem sido pouco explorada, e, como se pretende demonstrar, a compreensão do capítulo "A educação estética" pode ser ampliada, colocando-o em diálogo com o contexto do ensino de arte na Rússia logo após a revolução e na década de 1920.

Em termos metodológicos, operou-se por meio de pesquisa bibliográfica um diálogo entre essa obra de Vigotski e os historiadores da arte que pesquisaram o ensino de arte antes da Revolução de outubro, especialmente os trabalhos de Blakesley (2010), Pevsner (2005) e Stites (2005), somados à historiografia sobre as escolas de arte criadas após 1917 (Bojko, 1980; Gough, 2005; Lodder, 1983, 1992, 2005; Misler, 1997a, 1997b;). Orientaram as análises as seguintes questões: as ideias de Vigotski sobre estética estavam em consonância com as práticas de arte-educação estabelecidas nessas novas instituições? Como essas ideias se relacionavam com as políticas para a arte-educação no período? Para responder tais perguntas, primeiramente é apresentado o contexto do ensino da arte no período imperial; em seguida, são apresentados dados sobre a completa reestruturação do ensino de artes na Rússia após a Revolução de outubro de 1917; por fim, são evidenciados possíveis diálogos entre "A educação estética" de Vigotski e essas diversas iniciativas no âmbito da arte-educação.

\section{A primeira escola de arte:}

\section{a Academia Imperial de São Petersburgo}

O grau de transformação do ensino de arte na Rússia após a revolução só pode ser avaliado, ao se ter ideia sobre como se dava o ensino da arte no período anterior. Até meados do século XVIII, não havia uma escola de arte russa (Blakesley, 2010). Embora houvesse tradicionais escolas formadoras de pintores de ícones, esses eram vistos como objetos sagrados, não como obras de arte. A primeira Academia de Artes foi fundada em 1757, e desde seus princípios, o ensino de arte na Rússia Imperial foi marcado por forte influência estrangeira: primeiramente alemã e depois francesa, a partir do reinado de Elizabeth (1741-62). Para a Rússia aristocrática, os hábitos franceses serviam de padrão e muitos nobres comunicavam-se em francês - em detrimento da língua russa - até pouco antes da revolução de 1917 (Blakesley, 2010). 


\section{pro.posições}

Uma característica importante da sociedade russa, refletida também no pertencimento de classe dos alunos da Academia, era a divisão social entre nobreza, burguesia, clero e camponeses. Os camponeses eram absoluta maioria da população, sendo a porcentagem de servos de 49\%, segundo o primeiro censo do país, em 1857. O perfil do ingressante na Academia modificou-se ao longo do tempo, inclusive com a proibição da entrada de servos em alguns períodos, como em 1817. O regime servil surgiu na Rússia no século XVI, sendo estabelecido pelo costume de normas de direito privado e éditos governamentais, os quais foram, aos poucos, cerceando os direitos dos servos, especialmente no que tange à sua mobilidade. A desigualdade social era enorme, uma vez que os impostos que mantinham a rígida organização social eram pagos exclusivamente pelas classes menos privilegiadas, isentos os nobres e os burgueses (Tragtenberg, 2007). A entrada de servos na Academia, quando admitida, estava subordinada à concessão de sua liberdade ao completar a formação artística. A partir de 1859, a Academia passou a admitir estudantes de qualquer posição social (Blakesley, 2010).

Desde 1722, vigia a tabela de posição social que estratificava o serviço público e militar em 14 categorias. Essa rígida estratificação só foi abolida, em novembro de 1917, após a Revolução. Estudantes da Academia Imperial e seus professores e diretores estavam enquadrados nesse sistema, sendo que o presidente ocupava a elevada posição IV (igual à recebida por um tenente-general no exército), enquanto aos graduandos era dada a posição mais baixa, grau XIV (Stites, 2005). Semelhante ao modelo francês, o artista acadêmico era um funcionário estatal, e a arte acadêmica, uma arte estatal, como afirmou Pierre Bourdieu (1998) a respeito da Academia francesa.

Os alunos seguiam um intenso horário de atividades relativas à opção designada (pintura, escultura, arquitetura; ou as opções de ofícios profissionais - destinadas a estudantes com desempenho insuficiente para seguir as opções mais elevadas -, como trabalho em metal, fabricação de relógios e marcenaria), complementadas por disciplinas como matemática, anatomia, geografia, mitologia (Pevsner, 2005). Línguas estrangeiras eram também ensinadas e muitos professores sequer falavam russo, comunicando-se exclusivamente em francês. A maioria dos títulos na biblioteca da escola era igualmente em língua estrangeira (Blakesley, 2010). 


\section{pro.posıções}

O currículo contava com atividades como cópias de gravuras e desenhos aprovados, desenho com modelos em gesso e cópia de pinturas. Somente quando dominadas essas áreas, poder-se-ia então frequentar as aulas de modelo vivo e, finalmente, iniciar composições a óleo. Os acadêmicos eram submetidos a exames regulares, nos quais apresentavam desenhos a seus professores, e eram encorajados a completar composições para concorrer às medalhas de ouro e prata. A medalha de ouro dava direito a viajar para a Europa, geralmente para Roma, com patrocínio do governo. Como no modelo francês, a Academia russa preconizava os seguintes aspectos: "desenho, perspectiva linear, modelado, figuras estereotipadas, imitação escrupulosa de pequenos detalhes, acessórios arqueológicos, narrativa, fontes textuais" (Stites, 2005, p. 294) e especialmente o "acabamento", com o predomínio da linha sobre a cor, nenhum indício de pincelada, nem bordas irregulares. Essa instituição formou cerca de dois mil artistas desde sua fundação até 1861 (Stites, 2005).

Em 1863, 13 alunos da Academia rebelaram-se contra o tema originário da mitologia nórdica "A entrada de Wotan no Walhalla" para a competição da seção histórica da Medalha de Ouro Anual, prêmio máximo da Academia. Esses estudantes argumentavam que tal tema estava completamente divorciado das exigências contemporâneas e sociais, e se desligaram da Academia em sinal de protesto. Bowlt (1983) aponta que esse cisma foi influenciado pelos programas estéticos e sociopolíticos de Nikolai Tchernishevski, partidário de uma estética realista e de uma arte subordinada à vida, às demandas sociais reais, perspectiva incompatível com a orientação geral do ensino na Academia.

Em 1870, esses artistas criaram uma sociedade chamada "Sociedade de Exibições Itinerantes" e ficaram conhecidos como "Itinerantes", uma vez que pretendiam, com exposições itinerantes para o campo, "levar a arte para o povo" (Gray, 1962, p. 9). A importância da ruptura empreendida pelo grupo não pode ser diminuída, pois, semelhante ao contexto francês, descrito por Pierre Bourdieu (1998), implicou na "instituição da anomia”, e a Academia perdeu a prerrogativa exclusiva de nomeação do artista.

Em Moscou, a opção para quem desejasse estudar arte era a Escola de Pintura e Escultura, fundada em 1840. Mais liberal que a Academia, não dependia de patrocínio da corte, sendo sustentada com apoio privado. Desde 1850, a escola de Moscou apresentava uma organização diferente da de São Petersburgo, com escolha livre de temas e ênfase no estudo da natureza, abordagem quase ausente na Academia (Gray, 1962). Essa escola foi catalisadora 


\section{pro.posições}

de muitos encontros prolíficos da vanguarda russa, como o poeta Alexei Kruchenykh, os artistas Vladimir e Davi Burliuk, e Vladimir Maiakovski. Passaram ainda pela instituição o líder vanguardista Mikhail Larionov e o artista construtivista Vladimir Tatlin. Ateliês dirigidos por artistas individuais também representavam possibilidades de formação artística, e alguns nomes importantes da vanguarda russa praticamente não tiveram educação formal nas artes, como no caso do criador do Suprematismo, Kazimir Malevich. Também em Moscou, a Escola Stroganov de Arte Industrial oferecia formação voltada para ofícios.

\section{Reestruturando o ensino de arte na Rússia após}

\section{a Revolução de outubro de 1917}

A Revolução de 1917 criou a possibilidade de redefinir o sistema educacional da Rússia, qualificado como "decrépito" por Anatoli Lunacharski, escritor e teórico marxista, considerado uma das figuras mais importantes na completa restruturação da educação logo após a Revolução de outubro. Lunacharski foi indicado para o Comissariado para Instrução Pública (Narkompros), cargo que ocupou no período de 1917 a 1929. Nesse contexto particular da administração estatal pós-revolucionária, arte e educação estavam sob a mesma direção. Os discursos e os escritos de Lunacharski revelam a agenda para a educação, que incluía a descentralização da administração das escolas, a serem dirigidas por estudantes, professores e funcionários; a ideia da educação integrada na vida cotidiana; e a combinação de educação e trabalho (Rosenberg, 1984).

Dentre os objetivos das políticas educacionais estava o conceito de "escola integrada", a qual deveria conferir acesso amplo e contínuo à educação, do jardim de infância à universidade (Fitzpatrick, 1970). Além disso, era necessário erradicar o analfabetismo e oferecer educação formal aos trabalhadores. Novas instituições educacionais foram criadas para atender a essas demandas, como as "faculdades de trabalhadores" (rabfak), as "escolasfábricas" e as "organizações culturais proletárias" (proletkult). As atividades do proletkult combinavam células culturais nas fábricas, estúdios e workshops, assim como em clubes locais onde se realizavam performances, palestras, espetáculos de música e cursos de arte. Atenção adicional era dada à educação "fora da escola", cujo objetivo era o desenvolvimento de uma 


\section{pro.posıções}

cultura da classe trabalhadora/proletária e a "independência criativa das massas" (Kerzhentsev, 1984, p. 82).

A atuação pedagógica de Vigotski, assim como as atividades de caráter cultural que realizou em Gomel, atende a essas demandas gerais da educação e da arte do período. Após concluir sua formação em Direito, na Universidade de Moscou, e História e Filologia na Universidade Shanyavsky, de Moscou, em 1917, Vigotski retornou a Gomel, cidade onde viveu a infância e onde se engajou na construção de uma nova educação. O período de Gomel refere-se à sua produção entre 1917 e 1924, dirigida à educação, à crítica literária e teatral e à organização da produção teatral da cidade. Nesse período, assumiu um papel central na vida cultural da cidade, promovendo as "Segundas-feiras," encontros nos quais se discutiam literatura, artes visuais, filosofia. Além disso, lecionou em várias instituições públicas, incluindo disciplinas de estética para trabalhadores culturais rurais, e estética e teoria da arte no conservatório público. Outras disciplinas lecionadas foram língua russa e literatura (primeira escola soviética para trabalhadores; cursos para trabalhadores; cursos noturnos na escola provincial); lógica e psicologia (cursos em educação soviética para professores do pré-escolar; faculdade de professores; cursos de verão para capacitação docente) (Vigodskaya \& Lifanova, 1999). Importante para o objetivo deste artigo é o fato de Vigotski ter ensinado em duas instituições voltadas para a educação profissional no campo das artes aplicadas, na escola vocacional para tipógrafos e para trabalhadores de metal e aço (Vigodskaya \& Lifanova, 1999). Mais tarde, assumiu a seção de artes do departamento provincial de política educacional de Gomel.

Evidência da sintonia de Vigotski com as diretrizes educacionais no pós-revolução pode ser encontrada na ênfase dada pelo próprio Lunacharski à educação estética, mesmo nas formações de caráter mais técnico e comercial:

Para nós, educação estética está conectada com a educação técnica e física. E mesmo quando ensinamos ao marceneiro e ao metalúrgico, queremos preparar o jovem camarada não somente para seu ofício, mas para ser uma pessoa notável que pode construir a vida belamente. É assim que o socialista imagina a si mesmo na escola do futuro. (citado por Rosenberg, 1984, p. 32)

Entretanto, além de preconizar uma educação estética para contemplação e criação do belo, o governo bolchevique tinha objetivos mais pragmáticos, estabelecendo claramente que todos os campos da arte deveriam "ser utilizados para elevar e ilustrar claramente nosso 


\section{pro.posições}

trabalho de propaganda agitacional política e revolucionária", uma vez que a "arte é um meio poderoso de infectar os que estão ao nosso redor com ideias, sentimentos e humores" (Lunacharsky \& Slavinsky, 1976, pp.184185). As atividades profissionais culturais e artísticas deveriam ser dirigidas para a criação de "formas de arte e instituições puramente proletárias" (p. 185).

A revolução bolchevique abriu campo para uma total redefinição do ensino de arte na Rússia. O papel da vanguarda artística nessa redefinição é absolutamente sem precedentes na história da arte. Quando o Narkompros foi estabelecido, alguns dos maiores expoentes da vanguarda russa foram chamados para compor os quadros administrativos das novas instituições (Lodder, 1983). Lunacharski nomeou o artista David Shterenberg para dirigir a Seção de Artes Plásticas (I₹o), que contou com membros do calibre de Kandinsky, Maiakovski, Malevich, Natan Altman, Nikolai Punin, Ossip Brik, e Tatlin.

\section{Estúdios de Arte Livres (Svomas)}

As instituições artísticas existentes foram totalmente reorganizadas. A Academia Imperial de Arte foi abolida em Petrogrado, ${ }^{2}$ assim como a Escola de Pintura, Escultura e Arquitetura de Moscou e a Escola Stroganov. Todas foram fundidas na criação do Primeiro e Segundo Estúdios de Arte Livres (Svomas), em dezembro de 1918. O formato desses Estúdios baseava-se na ideia expressa por Shterenberg de que "a arte é ilimitada e indefinida, é impossível ensiná-la: a única coisa possível a fazer é oferecer os ateliês livres e gratuitos do Estado àqueles que têm necessidade e que desejem estudar o ofício artístico" (citado por Marcadé, 2007, p. 198). O cartaz de abertura do Svomas de Moscou proclamava

a existência livre de todas as correntes artísticas", e ainda "o desenvolvimento da individualidade de cada um segundo suas escolhas, a eleição dos diretores pelos alunos, a gratuidade total, a possibilidade de todo cidadão com mais de 16 anos de se inscrever sem nenhuma atestação e de se beneficiar da gratuidade durante sete anos no máximo. (Marcadé, 2007, p. 198)

A pluralidade de linhas artísticas era um traço marcante da escola. Inicialmente os alunos podiam escolher livremente seus professores, e até mesmo frequentar um estúdio sem

\footnotetext{
${ }^{2}$ A cidade de São Petersburgo foi fundada em 1703 por Pedro, o Grande; mudou de nome para Petrogrado de 1914 a 1924; para Leningrado, de 1924 até 1991, quando voltou a chamar-se São Petersburgo.
} 


\section{pro.posıções}

professor. Importantes artistas da época dirigiram estúdios na escola, os quais estavam divididos nas categorias pintura, escultura e arquitetura (Lodder, 1983).

Com relação ao programa, cada professor tinha liberdade para desenvolver suas próprias abordagens, muitas das quais exploravam poéticas mais modernas: o método desenvolvido por Malevich, bem documentado em seus escritos e diagramas pedagógicos, consistia numa exploração do mesmo caminho autodidata traçado pelo próprio artista, que passou do Impressionismo para o Cubismo, Futurismo, até culminar no Suprematismo. ${ }^{3}$ Observa-se, então, um pluralismo metodológico, com afastamento das formas acadêmicas de ensino da arte e importante incorporação de poéticas progressistas, avant-garde, as quais, dentro do novo sistema de ensino, deixaram de estar marginalizadas e passaram a ser oficiais, institucionais, ainda que por um breve período, e não sem resistências de vozes mais conservadoras.

Esse modelo absolutamente flexível, numa clara oposição à rigidez acadêmica, mostrou-se por demais caótico. Em consequência, um pouco de estrutura foi imposta na escola: as mudanças de estúdios foram permitidas somente no primeiro mês de aula, e depois, somente uma vez por ano (Lodder, 1983). Ainda, como parte da política de descentralização da educação, os Estúdios Livres se espalharam por diversas províncias do território russo.

\section{Ateliês Superiores de Arte e Técnica (Vkhutemas)}

Em 1920, os Svomas foram absorvidos pelos Ateliês Superiores de Arte e Técnica (Vkhutemas), mais orientados para a indústria. O decreto instituindo a escola esclarecia seus objetivos, definindo-a como "uma instituição educacional especializada para o avanço do treinamento artístico e técnico, criada para preparar artistas mestres altamente qualificados para a indústria, assim como instrutores e diretores de educação profissional e técnica" (Lodder, 1983, p. 112).

A criação dos Vkbutemas marca uma nova direção apontada pelo governo bolchevique no que tange à estratégica incorporação das artes pela indústria, processo demandado pela necessidade urgente de reestruturação do setor. Ainda em 1918, foi criada no Narkompros uma subseção do I₹o para Arte e Produção, para promover o contato direto com representantes da

\footnotetext{
${ }^{3}$ Sobre a perspectiva desse artista com relação aos movimentos de arte moderna, ver Malevich $(1959,1969)$.
} 


\section{pro.posições}

indústria em suas diversas especializações (porcelana, vidro, gráfica, têxtil), na direção da política governamental da melhoria da qualidade da produção industrial (Lodder, 1983).

A estrutura e os programas de ensino nos Vkhutemas foram modificados várias vezes, e Lodder (1983) identifica três períodos na história da escola, divididos conforme a gestão de seus três reitores: o primeiro período (1920-23) caracterizou-se pela exploração, experimentação e necessária adequação do staff herdado dos Svomas para as tarefas de cunho industrial; o segundo período (1923-26) consolidou as experimentações do período anterior, inclusive com os workshops executando tarefas para indústrias; no terceiro período (1926-30), a escola tornou-se um instituto de treinamento mais estritamente técnico e industrial.

Em termos pedagógicos, o programa dos Vkhutemas era extremamente inovador, sendo a escola Bauhaus, na Alemanha, a única experiência paralela. ${ }^{4}$ Um elemento importante era o Curso Básico, no qual o estudante recebia uma formação básica (cuja duração variou entre dois anos a poucos meses), e depois frequentava as disciplinas relativas à especialização escolhida. O programa básico sofreu várias alterações ao longo da história da escola, mas a ênfase era principalmente nos aspectos formais, especialmente sobre formas abstratas, e compreendia, em divisões e combinações diversas, quatro focos de estudo (konsentry): Espaço, Volume, Cor e elemento Gráfico.

A escola tinha uma média de 1.500 alunos e, apesar da vocação industrial preconizada nos estatutos, havia mais alunos nas especializações em pintura e escultura que nas opções mais voltadas para produção (cerâmica, têxtil, metal, madeira), artes gráficas e arquitetura. A faculdade que chegou mais próximo do objetivo foi a de Trabalho em Madeira e Metal (Dermetfak), ainda que nesse momento a indústria soviética fosse mais uma promessa que uma realização. ${ }^{5}$

O Vkhutemas, assim como outras instituições do período, foi arena de muitos embates entre defensores e adversários da arte de produção. Observa-se, na história da escola, uma forte tendência construtivista e, pode-se dizer, produtivista, a qual pretendia constituir um profissional, cujo perfil poderia ser enquadrado na ideia do "artista-construtor". Entretanto, a ênfase nessa perspectiva não se deu sem acirrados debates no campo artístico, protagonizados por perspectivas opostas na arte russa, personificadas nas figuras de Kandinsky e Rodchenko,

\footnotetext{
${ }^{4}$ Para uma relação entre Vkhutemas e Bauhaus, ver Lodder (1992).

${ }^{5}$ Uma consequência da Guerra Civil entre 1918 e1921 foi o recrudescimento da produção industrial. A retomada do crescimento era difícil sem o investimento e a tecnologia estrangeiros. Em 1926, apenas a produção de energia elétrica cresceu, todos os demais setores industriais ficaram abaixo dos resultados obtidos antes da guerra (Reis Filho, 2003).
} 


\section{pro.posições}

cuja rivalidade se desenvolveu na constituição e no desenvolvimento de outra instituição, o Instituto de Cultura Artística (Inkhuk).

\section{Instituto de Cultura Artística (Inkhuk)}

Em paralelo à criação do Vkhutemas em maio de 1920, foi criado em Moscou o Instituto de Cultura Artística (Inkhuk), "um laboratório para investigação das propriedades e meios artísticos" (Bowlt \& Long, 1980, p. 31). O programa, estabelecido por Kandinsky e parcialmente baseado em sua obra Do espiritual na arte (1996), cuja versão final data de $1912^{6}$, voltava-se para a "criação de uma ciência que estudaria todos os aspectos das diferentes artes, suas interações, numa perspectiva da síntese das artes" (Marcadé, 2007, p. 207).

No Inkhuk, Kandinsky dirigiu uma pesquisa de caráter empírico, na qual aplicou com seus colegas um questionário, cujo objetivo era "deduzir as leis gerais operatórias da percepção humana da forma, com o intuito de chegar numa análise científica dos fundamentos psicológicos da expressão estética" (Gough, 2005, p. 30). O questionário investigava os sentimentos mobilizados na contemplação de uma obra de arte, seus elementos formais e os efeitos físicos e psicológicos das cores.

Entretanto, a abordagem de Kandinsky encontrou fortes resistências, especialmente diante do Grupo de Trabalho de Análise Objetiva, formado por L. Popova, Rodchenko, V. Bubnova, V. Stepanova, e apoiado pelo crítico Nikolai Punin, os quais dirigiram pesadas críticas ao enfoque de Kandinsky, (des)qualificando-o como "pseudo-científico", "psicologismo", “individualismo.” A dissidência acabou por levar à resignação de Kandinsky do Instituto em 1921, quando o artista redirecionou seus projetos para o estabelecimento da Academia Russa de Ciências Artísticas (Rakhn).

Com a saída de Kandinsky, o Inkhuk passou a ter sua política pedagógica dirigida por Rodchenko, e seu programa e investigações foram consagrados ao problema da "passagem da composição para a construção". Essa passagem foi empreendida por meio de "profundas experiências estéticas formais sobre construções espaciais" (Khan Magomedov, 2013, p. 11). A etapa seguinte, ocorrida junto com experiências estéticas formais, foi a implementação do

\footnotetext{
${ }^{6}$ Essa importante produção teórica de Kandinsky (1996) caracteriza-se pelo acento ao papel da intuição na criação artística, a uma associação da arte com vida interior e espiritual - em oposição a uma perspectiva materialista; assim como à formulação da ideia da arte como fruto de uma "necessidade interior" do artista.
} 


\section{pro.posıções}

conceito de "construção" nas diferentes esferas relativas ao espaço (arquitetura, objetos, propaganda visual, teatro, etc.), exercitando a passagem "da construção para a produção" (p.11). Em novembro de 1921, todos os Construtivistas de Moscou abandonaram a pintura de cavalete, buscando em graus diversos, inserir-se na produção industrial (Gough, 2005).

\section{Academia Russa de Ciências Artísticas (Rakhn)}

A Academia Russa de Ciências Artísticas (Rakhn) foi estabelecida em 1921. Kandinsky assumiu a vice-presidência da instituição e a direção do departamento físico-psicológico, para ser um "laboratório sintético", especialmente com a psicologia da percepção, psicopatologia e psicanálise (Misler, 1997a). A psicologia desempenhou um papel central na Rakhn, e sua importância pode ser verificada na afirmação de Lunacharski de que "a arte é um fenômeno psicológico", e a abordagem psicológica “é inteiramente apropriada e essencial” (Lunacharsky citado por Zhdan, 1997, p. 71).

Todas as ideias psicológicas de Kandinsky receberam atenção nas pesquisas e nos departamentos da Rakhn. O staff era composto de representantes de diferentes áreas psicologia, filosofia, física, psiquiatria, música, teatro, cinema, sociologia, história da arte, biologia, folclore - engajados num amplo espectro de atividades, como pesquisas teóricas e experimentais, seminários, palestras, publicações (Misler, 1997b). A agenda da Rakehn também compreendia pesquisas sintéticas. Pode-se pensar aqui não só na ideia de "síntese das artes" e transposição das fronteiras entre as linguagens artísticas, mas também na verdadeira transdisciplinaridade presente também na perspectiva de Vigotski.

Eram objetos de pesquisa na Academia: a psicanálise, o papel do inconsciente na criatividade, os estudos de hipnose e sonhos; a psicologia da percepção por meio da psicologia da Gestalt; a criatividade de doentes mentais; o desenho infantil. Na confluência entre psicologia e arte, Vigotski interessou-se por quase todos esses objetos de pesquisa científica: a relação arte e psicanálise é tema de um capítulo do Psicologia da arte (1998), enquanto o processo de criação artística e o desenho infantil são desenvolvidos em Imaginação e criação na infância (2009). Embora o foco não fosse o fenômeno artístico, no vigoroso estudo epistemológico "O significado histórico da crise em psicologia" (2004) e em outros estudos, Vigotski discute os fundamentos da psicologia da Gestalt. 


\section{pro-posıções}

Apesar de cercado por um grupo de pesquisadores que tinham muito em comum com sua perspectiva, em 1921 Kandinsky aceitou de pronto o convite para ensinar na escola Bauhaus na Alemanha. A Rakßhn foi renomeada Academia Estatal de Ciências Artísticas (Gakhn) em 1925, e deixou de funcionar em 1930, em consequência da intolerância e dos expurgos stalinistas.

Figura central dentre os psicólogos da Rakhn foi Georgii Chelpanov, fundador e diretor do primeiro instituto de psicologia de Moscou em 1912. Chelpanov defendia uma "psicologia empírica independente, livre de reducionismos filosóficos e fisiológicos" (Kozulin, 1994, p.80), e sua posição foi combatida logo após a revolução tanto pela reflexologia, representada por Vladimir Bekhterev, quanto pela nova psicologia marxista, defendida por Konstantin Kornilov. A perspectiva de Chelpanov, fortemente influenciada por Wilhelm Wundt, e identificada com o método introspectivo experimental, foi então considerada “idealista”, e após o "Primeiro Congresso de Psiconeurologia Pós-Revolucionário" em 1923, Chelpanov foi destituído do cargo de diretor do Instituto de Psicologia. A direção foi assumida por Kornilov, e Alexander Luria integrou a equipe chamada para a renovação do instituto, para a qual Vigotski juntar-se-ia a partir de 1924 (Rivière, 1985). Chelpanov trabalhou na Rakhn de 1921 a 1930, chefiando uma comissão de pesquisa sobre a psicologia da percepção e outra sobre a criatividade artística.

Digno de atenção para o propósito deste artigo é o fato de Vigotski ter apresentado na Rakbn seu artigo "Para um estudo da psicologia do ofício do ator," no qual "apresentou uma série de questões metodológicas relativas às fronteiras e metodologias da atuação" " (Zhdan, 1997, p. 73). Zhdan afirma que, embora a obra Psicologia da arte de Vigotski tenha sido publicada somente em 1965, ou seja, 40 anos após ter sido produzida, seu trabalho era "bem conhecido por historiadores da arte e por eles respeitado" (p. 70).

Apresentado o panorama do ensino das artes antes e após a revolução bolchevique, é possível estabelecer os diálogos entre as ideias de Vigotski sobre o ensino da arte e esse cambiante contexto educacional.

\footnotetext{
${ }^{7}$ Infelizmente Zhdan (1997) não faz referência à data dessa apresentação de Vigotski.
} 


\section{pro.posıções}

\section{“A educação estética” de Vigotski}

Vigotski (2001) inicia seu escrito afirmando que a questão "da natureza, do sentido e dos métodos da educação estética” (p. 323), debatida entre a psicologia e a pedagogia, ainda não havia sido resolvida. Apresenta as posições da psicologia e da pedagogia, oscilando entre a negação do sentido educativo das vivências estéticas, a tendência de ver nelas a solução de "todos os problemas difíceis e complexos da educação" (p. 323) e o sentido da estética como "distração e satisfação" (p. 324). Para Vigotski, em todas essas posições, a estética aparece subordinada a cumprir funções alheias, especialmente "educar o conhecimento, o sentimento ou a vontade moral" (p. 324).

O primeiro aspecto abordado por Vigotski (2001) é a relação entre moral e arte. A literatura infantil com finalidade moral é diretamente atacada pelo autor, que demanda o abandono da concepção "segundo a qual as emoções estéticas têm alguma relação direta com as morais e toda obra de arte encerra uma espécie de impulso para o comportamento moral" (p. 325). A crítica de Vigotski mira a produção literária para crianças e, por meio da reflexão sobre a recepção de fábulas no contexto da educação infantil, o autor elabora uma de suas perspectivas mais originais e atuais: a ideia da incerteza do tipo de efeito moral a ser provocado no leitor, o que o leva a afirmar o "fato psicológico da diversidade de possíveis interpretações e conclusões morais” (p. 327).

Vigotski (2001) aponta outro "equívoco" na educação estética, o de "impor à estética problemas e objetivos que the eram estranhos" (p. 328), de ordem social e cognitiva. Afirma reiteradamente sua autonomia, ao assinalar que "a pedagogia tradicional caiu num impasse nas questões da educação estética ao tentar impor objetivos inteiramente estranhos e não inerentes a essa educação" (p. 331).

Para além da discussão sobre o ensino da arte, Vigotski toca uma questão que vinha sendo objeto de grande debate no pós-revolução, a saber, a própria função e o papel da arte na nova sociedade em construção. Um impasse se estabeleceu: de um lado estava parte da vanguarda russa que havia empreendido um consistente movimento rumo à autonomia da arte, por exemplo nas poéticas não objetivas de Kandinsky e no Suprematismo de Malevich, perspectivas essas estabelecidas nas escolas de arte criadas a partir de 1918, com seus programas voltados para a investigação empírica dos elementos da arte e também sua reflexão teórica. De outro lado, porém, especialmente no grupo dos artistas construtivistas a partir de 


\section{pro.posições}

1921, a investigação artística levou à própria negação da arte, em direção à incorporação da criação artística pela produção industrial e ao design de objetos cotidianos para fabricação em massa. Ora, a oposição idealismo e materialismo nas artes encontra eco na polarização entre as abordagens idealista (Chelpanov) e materialista (Bekhterev) em psicologia na época de Vigotski.

Dialogicamente, como característica própria de seus escritos, Vigotski também incorpora uma reflexão semelhante à abordagem "sintética" das artes de Kandinsky quanto ao estudo do fenômeno artístico, desenvolvido em parte no Inkhuk e depois na Rakhn, ao referenciar pesquisas de psicólogos que estudam as propriedades cinestésicas das pinturas. Vigotski ressalta que

lemos um quadro mais com os músculos do que com os olhos; o efeito estético do quadro situa-se nas pontas dos dedos tanto quanto no olho, uma vez que fala à nossa imaginação tátil e motora não menos do que à imaginação visual. (p. 343)

Tal enunciação reforça um postulado apresentado pelo autor sobre a complexidade da recepção estética, processo composto de três momentos: uma estimulação, uma elaboração e uma resposta. Vigotski atesta a especialidade da reação aos estímulos estéticos, constitutiva da "natureza da vivência estética" (p. 331). E ainda que não estivessem claros esses mecanismos, Vigotski descreve-os como síntese das relações entre as partes do objeto estético, a mobilizar a memória, a associação do pensamento e a empatia, a projeção de conteúdos e os sentimentos no objeto de arte. Todas essas reações são então coordenadas e elaboradas, num processo que é também construtivo e criativo.

Observa-se claramente que o foco de Vigotski recai no espectador, mais que no criador, de forma semelhante às pesquisas empreendidas por Kandinsky quanto aos efeitos provocados pela obra de arte. Pode-se identificar a origem desse interesse do artista russo no seu período de formação em Munique, na Alemanha, quando se aproximou de August Endell, que empreendia pesquisas acerca dos efeitos de diferentes tipos de linha no observador. Tais pesquisas foram influenciadas pelo conceito de empatia (Einfüblung) e pela psicologia estética de Theodor Lipps, cuja investigação buscava explicação psicológica para o efeito das formas visuais (Weiss, 1979). Ainda no contexto alemão, pode-se mencionar o trabalho do historiador da arte Heinrich Wölfflin (1994), cuja tese Prolegômenos a uma psicologia da arquitetura, de 1886, afirmava que a tarefa da psicologia da arquitetura era descrever e explicar "o efeito emocional 


\section{pro.posições}

que essa arte é capaz de evocar com seus meios próprios” (p. 150). Ou seja, o interesse de Vigotski no efeito da arte era compartilhado por membros da vanguarda russa, cujo exemplo mais evidente foi Kandinsky, embora possam se encontrar referências também em Malevich (1959).

A questão da autonomia em oposição à aplicação da arte para fins outros é também tema sobre o qual Vigotski parece dialogar com expoentes de vertentes progressistas da vanguarda. Uma evidência direta desse diálogo aparece ao final do capítulo "Arte e vida" em sua obra Psicologia da arte, no qual cita o artigo "Sob a bandeira da construção da vida: uma tentativa de entender a arte de hoje", escrito por Nikolai Chuzhak para a revista Lef (Frente de Esquerda das Artes) de $1923 .{ }^{8}$ Vigotski (2001) incorpora parte desse ideário ao adotar a ideia de

introduzir a educação estética na própria vida. A arte transfigura a realidade não só nas construções da fantasia, mas também na elaboração real dos objetos e situações. A casa e o vestuário, a conversa e a leitura, e a maneira de andar, tudo isso pode servir igualmente como o mais nobre material para a elaboração estética. (p. 352)

Chuzhak (2009) define a arte como "um método construtor da vida quantitativamente individual, temporário e predominantemente emocional” (p. 121.). E afirma apaixonadamente:

A arte vai fluir junto com a vida; a arte vai penetrar na vida. E isso quer dizer que a arte não pode ser um tipo especial de ocupação, mesmo entendida como "trabalho," nem pode haver uma "obra de arte," [ênfases do autor] que seja separada do fluxo unificado da arte e da vida ou especialmente feita para ser assim. (p. 121)

Em “A educação estética", Vigostki enfrenta as mesmas dificuldades percebidas pelos artistas, críticos e teóricos de vanguarda, diante de uma iminente "dissolução da arte na vida" (Chuzhak, 2009, p. 121) e da afirmação da arte como algo irredutível a outros fins.

O leitor que busca uma definição de educação estética para Vigotski depara-se com as dificuldades típicas apresentadas por seu estilo, que mais problematiza e complexifica que explica. Mas “A educação estética” (1926/2001) fornece várias pistas do que Vigotski considerava essencial nesse campo, muito especialmente sua defesa da autonomia da educação estética.

A educação estética defendida por Vigotski compreende a criação artística na infância, e o autor menciona mais especificamente a criação literária, musical e o desenho infantil,

\footnotetext{
${ }^{8}$ A Lef existiu de 1923 a 1925. Retomada como Novyi Lef (Nova Frente das Artes) de 1927 a 1928, estava próxima dos construtivistas e formalistas (Bowlt, 1976, p. 199).
} 


\section{pro.posições}

enquanto a criação teatral aparece num texto mais tardio, Imaginação e criação na infância, publicado em 1930 na Rússia. Vigotski (2001) é claro ao postular que a educação deve "promover o sentimento estético" (p. 328) e propiciar a "educação de hábitos e habilidades estéticas” (p. 328). A criação artística na infância deve ser mediada pelo educador, e seu valor principal consiste mais no processo de criação que no produto final, que não deve ser equiparado à criação artística do adulto.

É possível aproximar os fundamentos da educação estética em Vigotski com sua definição de arte como "técnica social do sentimento" (1998, p. 315), pois o autor vê na criação infantil uma função de "ascensão do psiquismo" (2001, p. 346), de organização do comportamento. Essa definição de arte em Vigotski (2001) precisa ser compreendida em relação à noção de catarse, conceito que o autor retoma da "Poética" (1995) de Aristóteles e da psicanálise, e que consiste no "mecanismo biológico permanente e necessário de superação de excitações não realizadas na vida" (p. 338). Mas Vigotski amplia o conceito de catarse, ao compreendê-la como processo dialético no qual a emoção estética, específica das criações artísticas, "reconstrói o comportamento" (p. 345), é meio para vencer e superar vivências imediatas, abrindo possibilidades para torná-las vivências criadoras.

O processo de recepção estética é igualmente importante na educação estética de Vigotski, uma vez que o autor considera que o receptor é também um criador do objeto estético. O leitor/espectador recria a obra de arte no processo de recepção. Nesse sentido, a educação estética passa pelo ensino de habilidades técnicas, que permitirão ampliação da capacidade de "perceber e vivenciar obras de arte" (p. 346), assim como a educação do juízo estético, ligado à ideia de ampliar os âmbitos da experiência pessoal da criança, ao aproximá-la da "experiência estética da humanidade" (p. 352).

Em suma: em seus escritos Vigotski se mostra comprometido com o desenvolvimento de uma educação mais ampla e democrática, porém, ao atestar a autonomia da arte, afasta-se de uma perspectiva oficial que via na arte um instrumento de propagação ideológica. Em nenhum momento de sua produção esse ponto de vista aparece, e, ao contrário, sublinha a perspectiva polissêmica da recepção estética, posição que viria a ser contrária à instituição do decreto governamental, "Da reforma das organizações literárias e artísticas”, em 1932, a partir do qual o Partido Comunista passou a exercer controle sobre a vida artística do país, impondo a doutrina do Realismo Socialista a todos os campos da produção artística nacional. 


\section{pro-posıções}

ISSN 1980-6248

Por fim, cabe destacar que o capítulo "A educação estética" foi forjado na experiência prática de Vigotski em diálogo com a arte e a ciência de sua época. A qualidade das reflexões e dos princípios ali apresentados pauta-se em um pensamento independente dos encaminhamentos oficiais, aspecto que garante a atualidade e a potência de sua obra para pensar o ensino de arte hoje.

\section{Referências Bibliográficas}

Amorim, V. M., \& Castanho, M. E. (2008, dezembro). Por uma educação estética na formação universitária de docentes. Educação \& Sociedade, 29(105), 1167-1184.

Aristóteles. Poética. In Aristóteles, Horácio, \& Longino (1995). A poética clássica. (J. Bruna, trad., 6a ed., pp.17-52). São Paulo: Cultrix.

Barros, E. R. O. de, Camargo, R. C.de, \& Rosa, M. M. (2011, abr./jun.). Vigotski e o teatro: descobertas, relações e revelações. Psicologia em Estudo, 16, 229-240.

Blakesley, R. P. (2010, December). Pride and politics of nationality in Russia's Imperial Academy of Fine Arts, 1757-1807. Art History, 35(5) 800-835.

Blanck, G. (2003). Prefácio. In L. S. Vigotski. Psicologia pedagógica (pp.15-32). Porto Alegre: Artmed.

Bojko, S. (1980). Vkhutemas. In S. Barron, \& M. Tuchman The Avant-Garde in Russia, 19101930: new perspectives (pp.78-83). Los Angeles: The MIT Press.

Bourdieu, P. (1998). O poder simbólico (322 pp.). Rio de Janeiro: Bertrand do Brasil.

Bowlt, J. (ed.) (1976). Russian art of the avant-garde: theory and criticism 1902-1934 (360 pp.). New York: The Viking Press.

Bowlt, J. (1983). Russian painting in the nineteenth century. In T. G. Stavrou (Ed.), Art and culture in nineteenth century Russia (pp.113-139). Bloomington: Indiana University Press.

Bowlt, J., \& Long, R.-C. W. (1980). The life of Vasilii Kandinsky in Russian Art: a study of 'On the Spiritual in Art' (158 pp.). Newtonville, Mass.: Oriental Research Partners. 


\section{pro-posıções}

ISSN 1980-6248

Camargo, D. de, Bulgacov, Y. L. M. (2008). A perspectiva estética e expressiva na escola: articulando conceitos da psicologia sócio-histórica. Psicologia em Estudos [online], 13 (3), 467-475.

Chuzhak, N. F. (2009). Under the banner of life-building (An attempt to understand the art of today) (C. Lodder, trad.). Art in Translation,1(1), p. 119-151.

Fitzpatrick, S. (1970). The Commissariat of Enlightenment: soviet organization of arts and education under Lunacharsky, October 1917-1921 (380 pp.). Cambridge: University Press.

Gough, M. (2005). The artist as producer (257 pp.). Berkeley/Los Angeles: University of California Press.

Gray, C. (1962). The Russian experiment in art: 1863-1922 (296 pp.). New York: Harry Abrams.

Kandinsky, V. (1996). Do espiritual na arte (284 pp.). São Paulo: Martins Fontes.

Kerzhentsev, P. (1984). Out of school education and the "Proletkults" (Moscow, 1919). In W. G. Rosenberg (Ed.), Bolshevik visions: first phase of the cultural revolution in Soviet Russia (pp. 75-83). Michigan: The University of Michigan Press.

Khan Magomedov, S. O. (2013). L'InKhouK Naissance du constructivisme (381 pp.). Gollion: Infolio.

Kozulin, A. (1994). La psicología de Vygotski (294 pp.). Madrid: Alianza Editorial.

Lodder, C. (1983). Russian Constructivism (328 pp.). New Haven/London: Yale University Press.

Lodder, C. (1992). The Vkhutemas and the Bauhaus. In G. H. Roman, \& V. H. Marquardt (Ed.), The Avant-Garde Frontier: Russia meets the West, 1910-1930 (pp. 196-240). Gainesville, Flo: University Press of Florida.

Lodder, C. (2005). Constructive Strands in Russian Art 1914-1937 (589 pp.). London: The Pindar Press.

Lunacharsky, A., \& Slavinsky, Y. (1976). Theses of the Art Section of Narkompros and the Central Committee of the Union of Art Workers Concerning Basic Policy in the Field of Art (1920). In J. Bowlt. (Ed.), Russian Art of the Avant-Garde Theory and Criticism 19021934 (pp. 182-185). New York: The Viking Press.

Malevich, K. (1959). The Non-Objective World (101 pp.). Chicago: Paul Theobald and Company. 


\section{pro-posıções}

ISSN 1980-6248

Malevich, K. (1969). From Cubism and Futurism to Suprematism: The New Realism in Painting (Ot kubizma I futurizma do suprematizma. Novy zhivopisny realism.) (Third Edition. Moscow, 1916). In K. S. Malevich. Essays on Art: 1915-1933 (V. I, pp. 19-41). London: Rapp \& Whiting.

Marcadé, J.-C. (2007). L'Avant-Garde Russe (479 pp.). Paris: Flammarion.

Martins, J. B.(2010, abril). A importância do livro Psicologia Pedagógica para a teoria histórico-cultural de Vigotski. Aná, 28 (2), 343-357.

Misler, N. (1997a). Vasilii Kandinsky at RAKhN. In J. Bowlt, \& N. Misler, (Eds.), RAKhN: The Russian Academy of Artistic Sciences. Experiment, 3, 148-156.

Misler, N. (1997b). A Citadel of Idealism: RAKhN as a Soviet Anomaly. In J. Bowlt, \& N. Misler. (Eds.), RAKhN: The Russian Academy of Artistic Sciences. Experiment, 3, 1430.

Pereira, M. de A. (2012). Performance e educação: relações, significados e contextos de investigação. Educação em Revista [online], 28 (1), 289-312.

Peric, T. (2013). No exercício da arte: o professor criador. Diálogo entre o fazer artístico e a prática pedagógica. Pro-Posições [online], 24 (2), 195-220.

Pevsner, N. (2005). Academias de Arte: passado e presente (439 pp.). São Paulo: Martins Fontes.

Pino, A. (2006). A produção imaginária e a formação do sentido estético. Reflexões úteis para uma educação humana. Pro-Posições, 17 (2), 47-70,

Pino, A., Schlindwein, L. M., \& Neitzel, A. de A. (Org.), (2010). Cultura, escola e educação criadora. Formação estética do ser bumano (1a ed., 220 pp.). Curitiba: Editora CRV.

Reis Filho, D. A. (2003). As revoluções russas e o socialismo soviético (179 pp.). São Paulo: UNESP.

Rivière, A. (1985). La psicología de Vygotski (100 pp.). Madrid: Visor Libros.

Rosenberg, W. G. (1984). Introduction. In W. G. Rosenberg. (Ed.), Bolshevik Visions: First Phase of the Cultural Revolution in Soviet Russia (pp. 16-21). Michigan: The University of Michigan Press.

Stites, R. (2005). Serfdom, Society, and the Arts in Imperial Russia: The Pleasure and the Power (586 pp.). New Haven; London: Yale University Press. 


\section{pro.posıções}

ISSN 1980-6248

Toassa, G. (2013a, jan./abr.). A "Psicologia pedagógica" de Vigotski - considerações introdutórias. Nuances: estudos sobre educação, 24 (1), 64-72. Retirado em 23 de junho de 2014, de http://dx.doi.org/10.14572/nuances.v24i1.2155

Toassa, G. (2013b, setembro). Certa unidade no sincrético: considerações sobre educação, reeducação e formação de professores na "Psicologia Pedagógica" de L. S. Vygotsky. Estudos em Psicologia, 18 (3). Retirado em 23 de junho, de http://dx.doi.org/10.1590/S1413-294X2013000300010.

Tragtenberg, M. (2007). A revolução russa (155 pp.). São Paulo: UNESP.

Vigodskaya, G. L. \& Lifanova, T. M. (1999). Life and Works in 'Lev Semenovich Vygotsky', Journal of Russian and East European psychology, 37 (2), 23-90.

Vigotski, L. S. (1998). Psicologia da Arte (377 pp.). São Paulo: Martins Fontes.

Vigotski, L. S. (2001). A educação estética. In L. S. Vigotski, Psicologia pedagógica (pp. 323-363). São Paulo: Martins Fontes.

Vigotski, L. S. (2001) Psicologia pedagógica. São Paulo: Martins Fontes.

Vigotski, L. S. (2004). O significado histórico da crise em psicologia. Uma investigação metodológica. In L. S. Vigotski, Teoria e método em psicologia (pp. 203-417). São Paulo: Martins Fontes.

Vigotski, L. S. (2009). Imaginação e criação na infância (135 pp.). São Paulo: Ática.

Weiss, P. (1979). Kandinsky in Munich: The Formative Jugendstil Years (268 pp.). Princeton, New Jersey: Princeton University Press.

Wölfflin, H. (1994). Prolegomena to a Psychology of Architecture (1886). In H. F. Malgrave (Ed.), Empathy, Form and Space Problems in German Aesthesis $1873-1893$ (pp.149-192). Santa Monica, Ca: Getty Center for the History of Art and the Humanities.

Zhdan, A. (1997). Art History and Psychology at Rakhn: An Experiment in Collaboration. In J. Bowlt, \& N. Misler. (Eds.), RAKhN: The Russian Academy of Artistic Sciences. Experiment, 3,69-75.

Submetido à avaliação em 11 de novembro de 2014; aprovado para publicaşão em 22 de junho de 2015. 